Research Article

\title{
Model Test Research on the Influence of Gate Blocking in Siltation Environment
}

\author{
Hua Li $\mathbb{D},{ }^{1,2}$ Yifeng Wang, ${ }^{2}$ Jingyu Zhang $\mathbb{C}^{1},{ }^{1}$ Liangpeng Wan, ${ }^{2}$ Qiao Jiang, ${ }^{2}$ Hongyue Pan, ${ }^{2}$ \\ Yuanyuan $\mathrm{Hu}^{2}$ and Kun Wang ${ }^{2}$
}

${ }^{1}$ College of Hydraulic \& Environmental Engineering, China Three Gorges University, Yichang 443002, China

${ }^{2}$ China Three Gorges Projects Development Co., Ltd., Chengdu, Sichuan 610041, China

Correspondence should be addressed to Jingyu Zhang; zjy7268@sina.com

Received 25 November 2020; Revised 3 February 2021; Accepted 27 February 2021; Published 11 March 2021

Academic Editor: Bingxiang Yuan

Copyright (c) $2021 \mathrm{Hua} \mathrm{Li}$ et al. This is an open access article distributed under the Creative Commons Attribution License, which permits unrestricted use, distribution, and reproduction in any medium, provided the original work is properly cited.

\begin{abstract}
Aiming at the clogging problems encountered in the operation of deep-hole gates in high water level reservoirs and dams, this paper carried out a model test study on the influence of different materials and different siltation environments on the lifting of the gates and analyzed the rules of the effects of blockages in different siltation environments. An analysis model of the pull-out force of the gate (blocked object) considering the siltation environment was proposed in an innovative way and the similarity ratio relationship was verified. The results of the study show that (1) the size and time of the siltation and other factors have a significant influence on the pulling force of the blocked object. It increases with the increase of the siltation area. The longer the siltation goes on, the greater the pulling force will be. (2) As the similarity ratio $n$ increases, the calculation result of the analysis model is closer to the target value $n^{2}$ and it indicates that the theoretical model is reliable. The research results of this paper can provide certain guidance for deep-hole siltation dispatch to ensure project safety.
\end{abstract}

\section{Introduction}

According to incomplete statistics, China has now built more than 200 dams with heights above $100 \mathrm{~m}$ [1]. To meet the dispatching requirements of flood discharge and sand washing, most of these high dams and large reservoirs are equipped with deep-hole buildings, and their inlets are generally equipped with flat-plate overhaul gates, and the downstream outlets are equipped with arc-shaped working gates. When not in use, close the working gate to block the water, and then close the bulkhead gate to prevent siltation accumulation in the cave or even the cave body. When in use, open the bulkhead gate first, and then open the working gate $[2,3]$. Because the layout of deep holes is arranged at low altitude, and with the passage of operation time, the siltation at the inlet will continue to increase, and accidents may occur that the siltation affects the normal opening and closing of the gate, which seriously threatens the project safety [4].
At present, relevant studies have been made to analyze the source, characteristics, and influence of deep-hole inlet siltation. Relevant research [4] shows that the siltation in deep-hole inlet mainly includes silt, gravel, construction waste, and alluvial deposits. In order to study the impact of underwater siltation on the gate, Niu et al. [5] used a simulated gate to conduct a gate siltation friction test for the lift friction change of the gate in silted sediment. Xu and Ren [6] discussed how to determine the opening force of the gate in siltation condition through model tests. It is concluded that the fine-grained sediment upstream of the dam can be regarded as Bingham mud in most cases. According to the force balance condition of the silt in front of the dam, the silt similarity criterion is derived and the simulation test method is discussed. Hou other authors $[7,8]$ studied the influence of sedimentation on the opening process of the gate and the force and deformation of the gate panel through experiments and numerical simulations for the most widely used connecting automatic rod roller hydraulic control flap gate. 
$\mathrm{Wu}$ and Wang [9] studied the influence of siltation pressure on the opening of the gate when the hydraulic automatic control flap gate is applied in sediment-laden rivers.

At present, relevant research studies have been conducted focusing on the origin and characteristics of deephole inlet deposits, but there are few studies concerning about the influence of gate deposits under different sources and different boundary conditions. Based on this, this paper uses indoor model tests to study the influence of different materials on gate lifting under the underwater siltation environment, in order to provide corresponding guidance for deep-hole sediment dispatch to ensure project safety.

\section{Test Plan}

2.1. Test Equipment. At present, no relevant test equipment has been developed to simulate the impact of deep-water gate siltation. This paper combines the possible factors (silt source, silt height, silt time, silt contact area, etc.) with the gate affected by siltation. It conducts a test plan and combines with the existing conditions to design the test model. The schematic diagram of the test model is shown in Figure 1.

The blue area is the container of water, silt, steel plate, or steel bar, and the red area represents the dynamometer. The relevant dimensions are shown in Figure 1.

2.2. Test Plan. The main purpose of the test is to study the different materials' influence on the pulling of blocked objects under the underwater siltation environment, and it designs several sets of test plans for general law analysis.

According to the investigation and analysis, the main components of the deposits are gravel, mud, and sand. The content of concrete, scaffolding steel pipes, fasteners, construction templates, welding rods, steel bars, etc., is limited. In order to obtain more universal test results, these limiting factors will not be considered in this model test. Only mud, fine sand, coarse sand, sand gravel, and water are considered. Among them, the particle size of mud is $0 \mathrm{~mm} \sim 0.08 \mathrm{~mm}$, the particle size of fine sand is $0 \mathrm{~mm} \sim 5 \mathrm{~mm}$, the particle size of small stones is $5 \mathrm{~mm} \sim 20 \mathrm{~mm}$, and the particle size of medium stones is $20 \mathrm{~mm} \sim 40 \mathrm{~mm}$.

Among the test objects, three types of steel plates with different widths and three types of steel bars with different diameters are used as blocked objects for simulation: A1 steel plate $(800 \mathrm{~mm} \times 300 \mathrm{~mm} \times 10 \mathrm{~mm}), \quad$ A2 steel plate $(800 \mathrm{~mm} \times 200 \mathrm{~mm} \times 10 \mathrm{~mm})$, and A3 steel plate $(800 \mathrm{~mm} \times 100 \mathrm{~mm} \times 10 \mathrm{~mm})$, and B1 steel bar $(\phi 25 \mathrm{~mm} \times 800 \mathrm{~mm}), \mathrm{B} 2$ steel bar $(\phi 20 \mathrm{~mm} \times 800 \mathrm{~mm})$, and B3 steel bar $(\phi 16 \mathrm{~mm} \times 800 \mathrm{~mm})$.

In order to find the influence of different material source ratios, different siltation heights, different siltation times, and other factors on the pulling of the blocked material, four sets of experiments are designed: a single blocked material source at the same height's influence on the blocked material; the composition of different grades' source blockages' influence on the blocked material; different blockage heights' influence on the blocked material; and the same blockage height with different blocking times' influence on the blocked material. The specific plan is as follows:

(1) A test on the impact of a single blocked material source of the same height on the blocked material was carried out. The details are shown in Table 1.

(2) A test on the impact of blockage materials (mud, fine sand, small rocks, and medium rocks) with different gradations on the blocked objects was carried out. The details are shown in Table 2.

(3) A test on the impact of different plugging heights on the blocked objects based on the max proportion of the sources determined in the above experiments was carried out. The details are shown in Table 3.

(4) The test is conducted on the blocked objects' impact at the same blockage height with different blockage times based on the maximum source ratio of blockages determined in the above experiments. The details are shown in Table 4.

\section{Analysis of Test Results}

3.1. Influence Analysis of Single Source Silting. Simulation of the impact of a single blocked material source at the same height on the blocked material was carried out. The test results are shown in Table 5 .

It shows that whether it is a steel plate or a steel bar, under the action of a single blockage underwater, its pull-out force increases with the increase of the area of the blockage. Different blockages have different impacts on the pull-out force of the blockage. The difference is that the pull force in pure silt is the largest, followed by sand, medium rocks, and small rocks. In the water, it shows buoyancy, the size is approximately $10 \%$ of its own weight, and it is positively correlated with the wading area of steel plates and steel bars, which conforms to the general law.

Through sensitivity analysis, when the source is relatively single, the height of the blockage is the same, and when the width changes, the weight ratio of different blockages to the resistance of the steel plate is as follows: silt:sand:small stone:medium stone as $0.36: 0.26: 0.16: 0.22$; the weight ratio for the impact of the plugging resistance of the steel bar is as follows: silt: sand: small stone: medium stone as 0.30 : $0.26: 0.17: 0.27$. This result shows that the effect of silt on the resistance of blocked objects is more significant than that of sand and gravel, which can provide a quantitative reference for risk assessment.

3.2. Influence Analysis of Mixed Source Silting. The influence of silting of mixed sources (mud:sand:small stone: medium stone) with different grading material source mass ratios on the blocked material was analyzed (Table 6).

The test results show that whether it is a steel plate or a steel bar, under the condition of underwater mixed blockage, its pull-out resistance also increases with the increase of the blockage area, and the pull-out strength of different mixed silting substances is different, among which the pull-out 


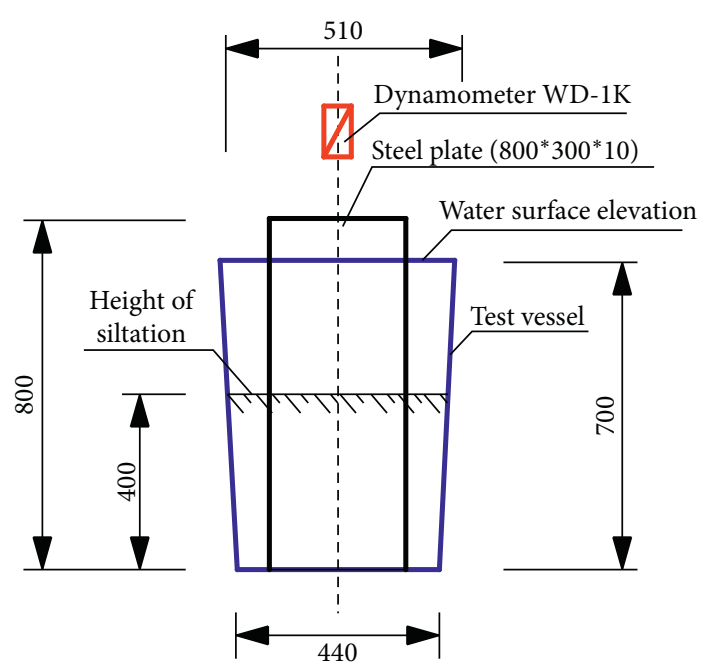

(a)

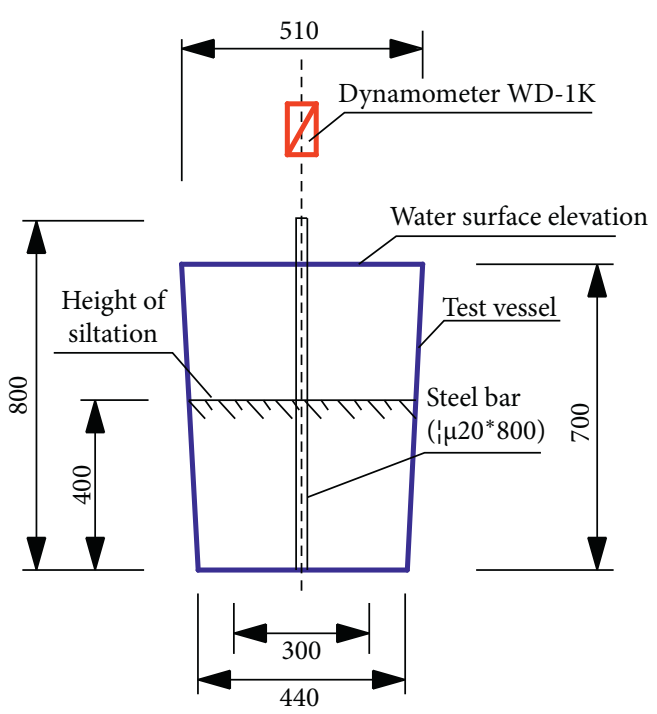

(b)

Figure 1: The schematic diagram of the test model.

TABle 1: Test parameters of a single blockage.

\begin{tabular}{lccccc}
\hline Blockage source & Water & Mud & Fine sand & Coarse sand & Sand gravel \\
\hline Blockage height $(\mathrm{m})$ /overall height $(\mathrm{m})$ & 0.7 & $0.4 / 0.7$ & $0.4 / 0.7$ & $0.4 / 0.7$ & $0.4 / 0.7$ \\
Time $(\mathrm{d})$ & 0 & 7 & 7 & 7 & 7 \\
\hline
\end{tabular}

TABLE 2: Test parameters of blockages with different gradation ratios.

\begin{tabular}{lccccc}
\hline Gradation ratio & Combination 1 & Combination 2 & Combination 3 & Combination 4 & Combination 5 \\
& $1: 1: 1: 1$ & $2: 1: 1: 1$ & $1: 2: 1: 1$ & $1: 1: 2: 1$ & $1: 1: 1: 2$ \\
\hline Blockage height $(\mathrm{m})$ /overall height $(\mathrm{m})$ & $0.4 / 0.7$ & $0.4 / 0.7$ & $0.4 / 0.7$ & $0.4 / 0.7$ & $0.4 / 0.7$ \\
Time (d) & 7 & 7 & 7 & 7 & 7 \\
\hline
\end{tabular}

TABLE 3: Test parameters of different blockage heights.

\begin{tabular}{lccccc}
\hline Blockage height $(\mathrm{m}) /$ overall height $(\mathrm{m})$ & $0.1 / 0.7$ & $0.2 / 0.7$ & $0.3 / 0.7$ & $0.4 / 0.7$ & $0.5 / 0.7$ \\
\hline Time $(\mathrm{d})$ & 7 & 7 & 7 & 7 & 7 \\
\hline
\end{tabular}

TABle 4: Test parameter table for different blocking times.

\begin{tabular}{lcccc}
\hline Blockage height $(\mathrm{m})$ /overall height $(\mathrm{m})$ & $0.5 / 0.7$ & $0.5 / 0.7$ & $0.5 / 0.7$ & $0.5 / 0.7$ \\
Time (d) & 7 & 14 & 21 & $0.5 / 0.7$ \\
\hline
\end{tabular}

strength of silt: sand: small rock: medium rock $=2: 1: 1: 1$ is the largest.

After normalization treatment, it can be seen that when the material source is a mixture source, the blockage height is the same, and when the width changes, the weight ratio of different blockages on the pull-out resistance of the blockage of steel plate type is as follows: combination 1: combination 2: combination 3: combination 4: combination $5=0.16: 031$ : $0.23: 0.15: 0.16$; the weight ratio of steel bar type affected by plugging resistance force is as follows: combination 1 : combination 2: combination 3: combination 4: combination
$5=0.14: 0.47: 0.16: 0.13: 0.10$. The results can provide a quantitative reference for risk assessment.

3.3. Analysis on the Effect of Sedimentation Height. The research results of the influence of different silting heights on the gate of the provenances composed of fixed gradations (silt: sand: small rock: medium rock $=2: 1: 1: 1$ ) are shown in Table 7.

The test results show that whether it is a steel plate or a steel bar, under the condition of underwater mixed silt, its 
TABLE 5: Test results of pull-out force of underwater blockage (single).

\begin{tabular}{lcccccccccc}
\hline $\begin{array}{l}\text { Blocked } \\
\text { objects }\end{array}$ & $\begin{array}{c}\text { Blockage } \\
\text { height } \\
(\mathrm{m})\end{array}$ & $\begin{array}{c}\text { Blockage + water/overall } \\
\text { height }(\mathrm{m})\end{array}$ & $\begin{array}{c}\text { Blocked objects' } \\
\text { contact area }\left(\mathrm{m}^{2}\right)\end{array}$ & $\begin{array}{c}\text { Blocked objects' } \\
\text { deadweight }(\mathrm{kN})\end{array}$ & $\begin{array}{c}\text { Pull-out force of blockage (kN) } \\
\text { Blank }\end{array}$ & $\begin{array}{c}\text { Silt } \\
\text { test }\end{array}$ & $\begin{array}{c}\text { Sand } \\
\text { Small } \\
\text { stone }\end{array}$ & $\begin{array}{c}\text { Medium } \\
\text { stone }\end{array}$ \\
\hline $\begin{array}{l}\text { l\# steel } \\
\text { plate }\end{array}$ & 0.4 & 0.7 & 0.240 & 0.173 & -0.016 & 0.486 & 0.333 & 0.208 & 0.297 \\
$\begin{array}{l}\text { 2\# steel } \\
\text { plate }\end{array}$ & 0.4 & 0.7 & 0.160 & 0.115 & -0.011 & 0.339 & 0.212 & 0.122 & 0.201 \\
$\begin{array}{l}\text { 3\# steel } \\
\text { plate }\end{array}$ & 0.4 & 0.7 & 0.080 & 0.057 & -0.006 & 0.171 & 0.105 & 0.062 & 0.099 \\
$\begin{array}{l}\text { 1\# steel bar } \\
\text { 2\# steel bar }\end{array}$ & 0.4 & 0.4 & 0.7 & 0.031 & 0.029 & -0.003 & 0.100 & 0.087 & 0.041 & 0.065 \\
3\# steel bar & 0.4 & 0.7 & 0.025 & 0.019 & -0.002 & 0.078 & 0.069 & 0.029 & 0.046 \\
\hline
\end{tabular}

TABLE 6: Test results of pull-out resistance of the lower gate of the underwater mixed blockage.

\begin{tabular}{|c|c|c|c|c|c|c|c|c|c|}
\hline \multirow{3}{*}{$\begin{array}{l}\text { Blocked } \\
\text { objects }\end{array}$} & \multirow{3}{*}{$\begin{array}{l}\text { Blockage } \\
\text { height } \\
\text { (m) }\end{array}$} & \multirow{3}{*}{$\begin{array}{c}\text { Overall } \\
\text { height } \\
(\mathrm{m})\end{array}$} & \multirow{3}{*}{$\begin{array}{l}\text { Blocked } \\
\text { objects' } \\
\text { area }\left(\mathrm{m}^{2}\right)\end{array}$} & \multirow{3}{*}{$\begin{array}{c}\text { Blocked } \\
\text { objects' } \\
\text { deadweight } \\
(\mathrm{kN})\end{array}$} & \multicolumn{5}{|c|}{ Pull-out force of blockage $(\mathrm{kN})$} \\
\hline & & & & & & Silt : sand: & mall stone: me & dium stone & \\
\hline & & & & & $\begin{array}{c}\text { Combination } \\
1 \\
1: 1: 1: 1 \\
\end{array}$ & $\begin{array}{c}\text { Combination } \\
2 \\
2: 1: 1: 1 \\
\end{array}$ & $\begin{array}{c}\text { Combination } \\
3 \\
1: 2: 1: 1 \\
\end{array}$ & $\begin{array}{c}\text { Combination } \\
4 \\
1: 1: 2: 1 \\
\end{array}$ & $\begin{array}{c}\text { Combination } \\
5 \\
1: 1: 1: 2 \\
\end{array}$ \\
\hline $\begin{array}{l}1 \# \text { steel } \\
\text { plate }\end{array}$ & 0.4 & 0.7 & 0.240 & 0.173 & 0.199 & 0.358 & 0.249 & 0.172 & 0.182 \\
\hline $\begin{array}{l}\text { 2\# steel } \\
\text { plate }\end{array}$ & 0.4 & 0.7 & 0.160 & 0.115 & 0.143 & 0.227 & 0.158 & 0.115 & 0.116 \\
\hline $\begin{array}{l}3 \# \text { steel } \\
\text { plate }\end{array}$ & 0.4 & 0.7 & 0.080 & 0.057 & 0.083 & 0.129 & 0.079 & 0.062 & 0.065 \\
\hline $\begin{array}{l}\text { 1\# steel } \\
\text { bar }\end{array}$ & 0.4 & 0.7 & 0.031 & 0.029 & 0.030 & 0.088 & 0.043 & 0.035 & 0.024 \\
\hline $\begin{array}{l}\text { 2\# steel } \\
\text { bar }\end{array}$ & 0.4 & 0.7 & 0.025 & 0.019 & 0.021 & 0.062 & 0.033 & 0.028 & 0.017 \\
\hline $\begin{array}{l}\text { 3\# steel } \\
\text { bar }\end{array}$ & 0.4 & 0.7 & 0.020 & 0.012 & 0.013 & 0.030 & 0.024 & 0.019 & 0.012 \\
\hline
\end{tabular}

TABLE 7: Results of pull-out force test of underwater (mixed) blockage.

\begin{tabular}{|c|c|c|c|c|c|c|}
\hline \multirow{3}{*}{$\begin{array}{l}\text { Blocked } \\
\text { objects }\end{array}$} & \multirow{3}{*}{ Overall height (m) } & \multirow{3}{*}{$\begin{array}{l}\text { Blocked objects' } \\
\text { deadweight (kN) }\end{array}$} & \multicolumn{4}{|c|}{ Pull-out force of blockage $(\mathrm{kN})$} \\
\hline & & & \multicolumn{4}{|c|}{ Silt $:$ sand $:$ small stone $:$ medium stone $=2: 1: 1: 1$} \\
\hline & & & $\begin{array}{c}\text { Blockage } \\
\text { height }(0.20 \mathrm{~m})\end{array}$ & $\begin{array}{c}\text { Blockage height } \\
(0.30 \mathrm{~m})\end{array}$ & $\begin{array}{c}\text { Blockage } \\
\text { height }(0.40 \mathrm{~m})\end{array}$ & Blockage height $(0.50 \mathrm{~m})$ \\
\hline 1\# steel plate & 0.70 & 0.173 & 0.181 & 0.287 & 0.358 & 0.419 \\
\hline 2\# steel plate & 0.70 & 0.115 & 0.106 & 0.174 & 0.227 & 0.285 \\
\hline $3 \#$ steel plate & 0.70 & 0.057 & 0.067 & 0.096 & 0.129 & 0.155 \\
\hline 1\# steel bar & 0.70 & 0.029 & 0.046 & 0.059 & 0.088 & 0.121 \\
\hline 2\# steel bar & 0.70 & 0.019 & 0.028 & 0.042 & 0.062 & 0.073 \\
\hline 3\# steel bar & 0.70 & 0.012 & 0.013 & 0.021 & 0.030 & 0.041 \\
\hline
\end{tabular}

pull-out resistance increases with the increase of the area of the blocked object and the increase of the height (or depth) of the blocked object. The higher the blockage, the greater the pull resistance.

3.4. Influence Analysis of Deposition Time. Table 8 shows the test results of the influence of different silting times on the lifting of the blocked material under the condition of the same silting height of $0.5 \mathrm{~m}$ for the provenance composed of fixed gradation (silt: sand : small rock : medium rock $=2: 1$ : $1: 1$ ).

The test results show that the pull-out strength of steel plate or steel bar increases with the area and time of blockage under the condition of underwater mixed silt. The longer the blockage time is, the greater the pull-out strength is.

Taking the 2:1:1:1 source composition ratio as an example, the weight of single factor on the lifting of the 
TABLE 8: Test results of pull-out force of underwater (mixed) sediment.

\begin{tabular}{|c|c|c|c|c|c|c|c|c|c|}
\hline \multirow{2}{*}{$\begin{array}{l}\text { Blocked } \\
\text { objects }\end{array}$} & \multirow{2}{*}{$\begin{array}{l}\text { Blockage }+ \text { water/ } \\
\text { overall height }(\mathrm{m})\end{array}$} & \multirow{2}{*}{$\begin{array}{l}\text { Blockage } \\
\text { height }(\mathrm{m})\end{array}$} & \multirow{2}{*}{$\begin{array}{c}\text { Blocked } \\
\text { objects' } \\
\text { area }\left(\mathrm{m}^{2}\right)\end{array}$} & \multirow{2}{*}{$\begin{array}{c}\text { Blocked } \\
\text { objects' } \\
\text { deadweight } \\
(\mathrm{kN})\end{array}$} & \multicolumn{5}{|c|}{$\begin{array}{c}\text { Pull-out force of blockage }(\mathrm{kN}) \\
\text { Silt }: \text { sand : small stone }: \text { medium stone }=2: 1: 1: 1\end{array}$} \\
\hline & & & & & $\begin{array}{l}\text { Blockage } \\
\text { time }(7 \mathrm{~d})\end{array}$ & $\begin{array}{l}\text { Blockage } \\
\text { time }(14 \mathrm{~d}\end{array}$ & $\begin{array}{l}\text { Blockage } \\
\text { time }(21 \mathrm{~d})\end{array}$ & $\begin{array}{l}\text { Blockage } \\
\text { time }(28 \mathrm{~d})\end{array}$ & $\begin{array}{l}\text { Blockage } \\
\text { time }(35 \mathrm{~d})\end{array}$ \\
\hline $\begin{array}{l}\text { 1\# steel } \\
\text { plate }\end{array}$ & 0.70 & 0.50 & 0.300 & 0.173 & 0.419 & 0.533 & 0.642 & 0.727 & 0.780 \\
\hline $\begin{array}{l}\text { 2\# steel } \\
\text { plate }\end{array}$ & 0.70 & 0.50 & 0.200 & 0.115 & 0.285 & 0.336 & 0.438 & 0.469 & 0.529 \\
\hline $\begin{array}{l}\text { 3\# steel } \\
\text { plate }\end{array}$ & 0.70 & 0.50 & 0.100 & 0.057 & 0.155 & 0.202 & 0.254 & 0.278 & 0.328 \\
\hline $\begin{array}{l}\text { 1\# steel } \\
\text { bar }\end{array}$ & 0.70 & 0.50 & 0.038 & 0.029 & 0.121 & 0.130 & 0.141 & 0.147 & 0.153 \\
\hline $\begin{array}{l}\text { 2\# steel } \\
\text { bar }\end{array}$ & 0.70 & 0.50 & 0.031 & 0.019 & 0.073 & 0.092 & 0.103 & 0.109 & 0.116 \\
\hline $\begin{array}{l}\text { 3\# steel } \\
\text { bar }\end{array}$ & 0.70 & 0.50 & 0.025 & 0.012 & 0.041 & 0.062 & 0.068 & 0.075 & 0.079 \\
\hline
\end{tabular}

blockage in the steel plate is as follows: blocking height: blocking time $=0.557: 0.065=0.9: 0.1$; The weight of the influence on the lifting of the steel bar type blockage is as follows: blockage height: blockage time $=0.188$ : $0.009=0.95: 0.05$. It can provide a quantitative reference for the risk assessment of deep-hole import accumulation.

\section{Research on the Analysis Model of Gate Pull- Out Force under Siltation Environment}

4.1. The Influence of Steel Plate Width on the Force of Blockage. As shown in Table 9, the influence of steel plate width on the force of silt is analyzed according to the first group of test results (take silt as an example).

It can be seen from Table 9 that, in the case of three plate widths and three circular cross sections, the calculated force of the blockage per unit plate width differs very little, which shows that the force of the blockage has no certain relationship with the width of the steel plate and the circular section size. The problem of gate clogging can be simplified to a two-dimensional problem [10].

Comparison of the pull-out force of different components per unit width shows that the force of circular crosssectional components is obviously greater than that of thin plate components, which is approximately 1.5 times.

4.2. The Influence of the Height of the Blockage against the Pulling Force. According to combination 2 in the second group of the test plan, the proportion of silt, sand, small stone, and medium stone is $2: 1: 1: 1$, its force to pull out is the largest under the same blockage height, and that is analyzed in the third group to compare the force of different blockage heights. As shown in Table 10, the influence of the height of underwater (mixed) sludge on the pull-out force is analyzed with the third group of test results.

It can be seen from Table 10 that, in the case of three steel plate widths, the difference in the force of the blockage per unit width at different blockage heights is very small, which is consistent with the results in Table 9, which further illustrates the plate width has little effect on the deposits' pull-out force. To analyze the blockage height's influence on the pull-out force, basing on the blockage force at the height of $0.2 \mathrm{~m}$, an analysis is carried out on the silt increment per unit width at intervals of $0.1 \mathrm{~m}$ corresponding to the increment of force. The result shows that as the height of the blockage gradually increases from $0.2 \mathrm{~m}$ to $0.5 \mathrm{~m}$ at intervals of $0.1 \mathrm{~m}$, the force increase gradually decreases in a nonlinear law, which can be better represented by a power function, as shown in Figure 2, that is, as the height of the blockage increases, the increase in the pull-out force per unit width increases in a nonlinear form of "first steep and then slow" [11].

In Figure 2, the incremental law of pull-out force for every $0.1 \mathrm{M}$ height increase of unit width is shown, and $h_{i}$ is defined as the distribution coefficient of the increase of silt force, which means that the increase of blockage per unit width per $0.1 \mathrm{~m}$ height corresponds to the increase in force. The corresponding calculation formula is shown as follows:

$$
h_{i}=0.1734 \times i^{-0.524} \text {, }
$$

where $i=0.1 \mathrm{~m}, 0.2 \mathrm{~m}, 0.3 \mathrm{~m}, 0.4 \mathrm{~m}$, and $0.5 \mathrm{~m}$, which represents the height of the blockage.

When the height of the blockage is very small, the blockage has a small restriction on the steel plate, and the corresponding siltation force should be small. Only when the height of the blockage increases to a certain level, the corresponding siltation force change law tends to be stable [12]. Since the test did not carry out the trial of the height of the blockage below $0.2 \mathrm{~m}$, analysis of the incremental distribution coefficient of the silt force below $0.2 \mathrm{~m}$ according to formula (1) showed that when $i$ was $0.1 \mathrm{~m}$, the $h_{0.1}$ was obviously large. Under the condition that the total pull-out force remains unchanged when the height of the blockage is $0.2 \mathrm{~m}$, the $h_{0.1}$ is modified to be $h_{0.1}=h_{0.1}-0.401$.

According to the previous analysis, it can be found that the width of the steel plate has little effect on the pull-out force of the silt, while the height of the silt has a significant impact on it. Based on this, the pull-out force of the silt can 
TABle 9: Analysis of the influence of plate width on the pull-out force of underwater (single) sediments.

\begin{tabular}{|c|c|c|c|c|c|c|}
\hline $\begin{array}{l}\text { Blocked } \\
\text { objects }\end{array}$ & $\begin{array}{l}\text { Blockage } \\
\text { height (m) }\end{array}$ & $\begin{array}{l}\text { Blockage + water/ } \\
\text { overall height }(\mathrm{m})\end{array}$ & $\begin{array}{c}\text { Blocked objects' } \\
\text { single-side area } \\
\left(\mathrm{m}^{2}\right)\end{array}$ & $\begin{array}{l}\text { Blocked objects' } \\
\text { deadweight }(\mathrm{kN})\end{array}$ & $\begin{array}{c}\text { Pull-out force of } \\
\text { blockage }(\mathrm{kN}) \\
\text { Silt }\end{array}$ & $\begin{array}{l}\text { Pull-out force of } \\
\text { blockage per unit width } \\
(\mathrm{kN} / \mathrm{m}) \\
\text { Silt }\end{array}$ \\
\hline $\begin{array}{l}\text { 1\# steel } \\
\text { plate }\end{array}$ & 0.4 & 0.6 & 0.240 & 0.173 & 0.486 & 1.960 \\
\hline $\begin{array}{l}\text { 2\# steel } \\
\text { plate }\end{array}$ & 0.4 & 0.6 & 0.160 & 0.115 & 0.339 & 2.018 \\
\hline $\begin{array}{l}3 \# \text { steel } \\
\text { plate }\end{array}$ & 0.4 & 0.6 & 0.080 & 0.057 & 0.171 & 1.943 \\
\hline $\begin{array}{l}\text { 1\# steel } \\
\text { plate }\end{array}$ & 0.4 & 0.6 & 0.031 & 0.029 & 0.100 & 3.185 \\
\hline $\begin{array}{l}\text { 2\# steel } \\
\text { plate }\end{array}$ & 0.4 & 0.6 & 0.025 & 0.019 & 0.078 & 3.105 \\
\hline $\begin{array}{l}3 \# \text { steel } \\
\text { plate }\end{array}$ & 0.4 & 0.6 & 0.020 & 0.012 & 0.061 & 3.035 \\
\hline
\end{tabular}

TABLe 10: Analysis of the influence of the height of underwater (mixed) silt.

\begin{tabular}{|c|c|c|c|c|c|c|c|c|c|c|c|c|}
\hline \multirow{3}{*}{ Blocked objects } & \multicolumn{4}{|c|}{ Pull-out force of blockage $(\mathrm{kN})$} & \multicolumn{4}{|c|}{$\begin{array}{l}\text { Pull-out force of blockage per unit } \\
\text { width }(\mathrm{kN} / \mathrm{m})\end{array}$} & \multicolumn{4}{|c|}{$\begin{array}{l}\text { Silt increment per unit width at } \\
\text { intervals of } 0.1(\mathrm{~m}) \text { corresponds to } \\
\text { the increment of force }(\mathrm{kN} / \mathrm{m})\end{array}$} \\
\hline & \multicolumn{4}{|c|}{ Blockage height $(\mathrm{m})$} & \multicolumn{4}{|c|}{ Blockage height (m) } & \multicolumn{4}{|c|}{ Blockage height (m) } \\
\hline & 0.2 & 0.3 & 0.4 & 0.5 & 0.2 & 0.3 & 0.4 & 0.5 & 0.2 & 0.3 & 0.4 & 0.5 \\
\hline $1 \#$ steel plate & 0.181 & 0.287 & 0.358 & 0.419 & 0.603 & 0.957 & 1.193 & 1.397 & - & 0.353 & 0.237 & 0.203 \\
\hline 2\# steel plate & 0.106 & 0.174 & 0.227 & 0.285 & 0.530 & 0.870 & 1.135 & 1.425 & - & 0.340 & 0.265 & 0.290 \\
\hline $3 \#$ steel plate & 0.067 & 0.096 & 0.129 & 0.155 & 0.670 & 0.960 & 1.290 & 1.550 & - & 0.290 & 0.330 & 0.260 \\
\hline Average & - & - & - & - & 0.601 & 0.929 & 1.206 & 1.457 & - & 0.328 & 0.277 & 0.251 \\
\hline
\end{tabular}

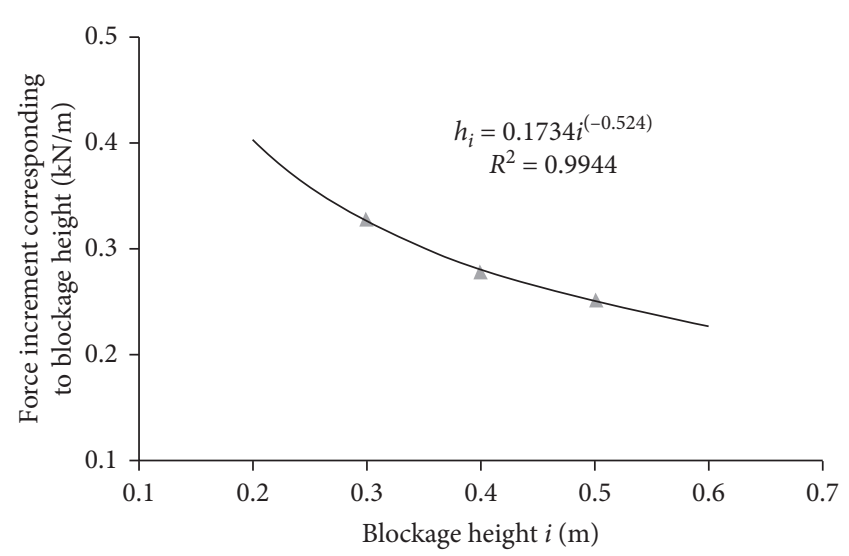

FIGURE 2: The force increment curve corresponding to the silt increment per unit width at intervals of $0.1 \mathrm{~m}$.

be simplified to a two-dimensional problem in height direction. Furthermore, the formula for calculating the pullout force of the blockage is obtained as follows:

$$
F=\Sigma h i \times b,
$$

where $b$ is the width of the steel plate.

According to formula (2), the test results of different plate widths and different blockage heights are verified and analyzed, as shown in Table 11.
From the analysis results in Table 11, it is shown that the calculation result of formula (2) coincides with the actual measured value. The error is relatively large at the blockage height of $0.2 \mathrm{~m}$. As the blockage height increases, the error gradually decreases and it can be controlled within $10 \%$ on the whole.

4.3. The Influence of Blocking Time against the Pulling Force. According to the test results of the fourth group, the calculated force of the blockage per unit width is shown in Table 12 .

It can be seen from Table 12 that, in the case of three steel plate widths, the overall difference in blockage force per unit width under different blockage times is small. In comparison, when the width of the steel plate is $100 \mathrm{~mm}$, the blockage force per unit width is relatively large. When the width of the steel plate increases to $200 \mathrm{~mm}$ and above, the blockage force per unit width tends to be stable. It shows that when the width of the steel plate is small, the width has a certain influence on the distribution law of the pulling force. When the width increases to 200, its influence gradually disappears. The pull-out force of the blockage per unit width tends to be stable under different blockage times, which is consistent with the distribution law of Tables 9 and 10, and it is reasonable to assume that it is a two-dimensional problem when the plate width is not less than $200 \mathrm{~mm}$. As the blocking time increases, the pull-out force gradually 
TABLE 11: Verification analysis of the pull-out force of underwater (mixed) silt.

\begin{tabular}{|c|c|c|c|c|c|c|c|c|c|c|c|c|}
\hline \multirow{3}{*}{ Blocked objects } & \multirow{2}{*}{\multicolumn{4}{|c|}{$\begin{array}{c}\text { Measured value of blockage pull- } \\
\text { out force }(\mathrm{kN}) \\
\text { Blockage height }(\mathrm{m})\end{array}$}} & \multirow{2}{*}{\multicolumn{4}{|c|}{$\begin{array}{c}\text { Calculated value of blockage pull- } \\
\text { out force }(\mathrm{kN}) \\
\text { Blockage height }(\mathrm{m})\end{array}$}} & \multicolumn{4}{|c|}{ Calculation error } \\
\hline & & & & & & & & & \multicolumn{4}{|c|}{ Blockage height (m) } \\
\hline & 0.2 & 0.3 & 0.4 & 0.5 & 0.2 & 0.3 & 0.4 & 0.5 & 0.2 & 0.3 & 0.4 & 0.5 \\
\hline $1 \# \mathrm{~s}$ & 0.181 & 0.287 & 0.35 & 0410 & 0.180 & 0270 & 0.364 & 0.440 & $-0.30 \%$ & $-2.65 \%$ & $1.75 \%$ & $4.91 \%$ \\
\hline $2 \# \mathrm{st}$ & 0.106 & 0.174 & 0.227 & 0.285 & 0.120 & 0.186 & 0.243 & 0.293 & $13.50 \%$ & $7.05 \%$ & $6.98 \%$ & $2.83 \%$ \\
\hline $3 \#$ steel plate & 0.067 & 0.096 & 0.129 & 0.155 & 0.060 & 0.093 & 0.121 & 0.147 & $-10.22 \%$ & $-2.98 \%$ & $-5.88 \%$ & $-5.47 \%$ \\
\hline
\end{tabular}

TABLE 12: Impact analysis of underwater (mixed) siltation time.

\begin{tabular}{|c|c|c|c|c|c|c|c|c|c|c|}
\hline \multirow{3}{*}{ Blockage objects } & \multicolumn{5}{|c|}{ Measured value of blockage pull-out force $(\mathrm{kN})$} & \multicolumn{5}{|c|}{ Blockage force per unit width $(\mathrm{kN} / \mathrm{m})$} \\
\hline & \multicolumn{5}{|c|}{ Time $(\mathrm{d})$} & \multicolumn{5}{|c|}{ Time $(\mathrm{d})$} \\
\hline & 7 & 14 & 21 & 28 & 35 & 7 & 14 & 21 & 28 & 35 \\
\hline 1\# steel plate & 0.419 & 0.533 & 0.642 & 0.727 & 0.780 & 1.397 & 1.777 & 2.140 & 2.423 & 2.600 \\
\hline 2\# steel plate & 0.285 & 0.336 & 0.438 & 0.469 & 0.529 & 1.425 & 1.680 & 2.190 & 2.345 & 2.645 \\
\hline 3\# steel plate & 0.155 & 0.202 & 0.254 & 0.278 & 0.328 & 1.550 & 2.020 & 2.540 & 2.780 & 3.280 \\
\hline Average & - & - & - & - & - & 1.457 & 1.826 & 2.290 & 2.516 & 2.842 \\
\hline
\end{tabular}

increases, and it can be better expressed by a power function, as shown in Figure 3.

According to Figure 3, the pull-out force of steel plate deposits per unit width varies with time and $g_{d}$ is defined as the correction coefficient considering the blocking time:

$$
g_{d}=0.4349 \times t^{0.4171},
$$

where $t$ represents the blocking time (unit: $\mathrm{d}$ ).

4.4. Model Analysis of Blocked Object Force in Siltation Environment. On the basis of formula (2), the multiplication of $g_{d}$ leads to the effect of silt consolidation time:

$$
F_{d}=\Sigma h i \times b \times g_{d} .
$$

Substituting formulae (1) and (3) in formula (4), we have

$$
F_{d}=0.4349 \times\left(\Sigma 0.1734 i^{-0.524}\right) \times b t^{0.4171},
$$

where $i$ can be $0.1 \mathrm{~m}, 0.2 \mathrm{~m}, 0.3 \mathrm{~m}, 0.4 \mathrm{~m}$, and $0.5 \mathrm{~m}$, which represents the height of the blockage.

According to formula (5), the test results of different blocking times are being analyzed, as shown in Table 13.

From the analysis results in Table 13, the calculation result of formula (4) coincides with the actual measured value. In comparison, the error is relatively large when the width of the steel plate is small. As the width of the steel plate increases, the error gradually decreases and it can be controlled within $10 \%$ on the whole.

\section{Verification of the Gate Silt Pull-Out Force Model}

5.1. Research on the Model Test Time Scale. In the gate siltation test, the initial physical quantities that need to be simulated include gate size, gate weight (controlled by thickness), blockage ratio, blockage content, blockage time, blockage height, and water level. Fuglsang and Ovesen gave

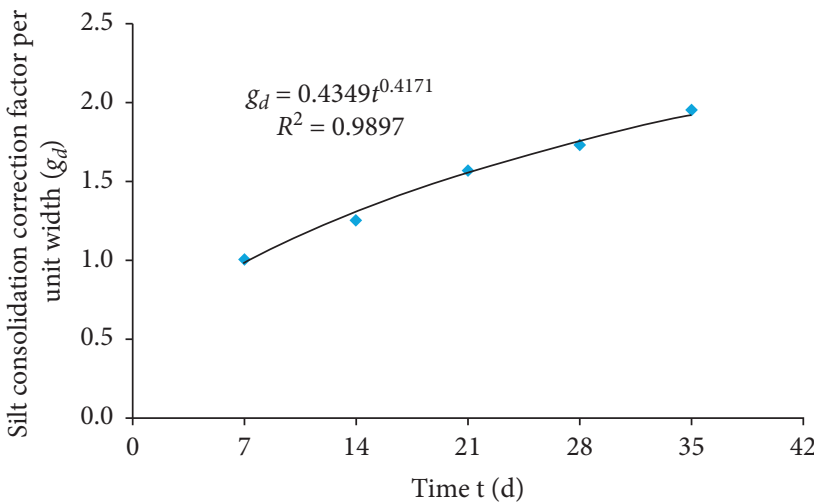

Figure 3: The pull-out force (normalized) of steel plate deposits per unit width varies with time.

the model similarity rate of common physical quantities in geotechnical model tests, as shown in Table 14 .

Table 14 shows that, for most physical quantities, the proportional relationship between the prototype and the model is certain, but for time, there are different proportional relationships corresponding to different physical phenomena.

For any force, there is the following relationship:

$$
\frac{F_{p}}{F_{m}}=\frac{\sigma_{p} \cdot A_{p}}{\sigma_{m} \cdot A_{m}}=n^{2},
$$

where $F_{p}$ and $F_{m}$ are, respectively, the prototype force and the model one. $A_{p}$ and $A_{m}$ are, respectively, the prototype area and the model one.

For the deep water gate siltation simulation test, the media influence of water is involved, and the degree of silt clogging is controlled by external factors such as seepage force and inertial force.

5.1.1. Scale of Model Test Time considering Seepage Force. In the model test, the seepage force was considered as the main factor, due to 
TABLE 13: Verification analysis of the pull-out force of underwater (mixed) silt.

\begin{tabular}{|c|c|c|c|c|c|c|c|c|c|c|c|c|c|c|c|}
\hline \multirow{3}{*}{ Blocked objects } & \multirow{2}{*}{\multicolumn{5}{|c|}{$\begin{array}{c}\text { Measured value of blockage pull- } \\
\text { out force }(\mathrm{kN}) \\
\text { Time }(\mathrm{d})\end{array}$}} & \multirow{2}{*}{\multicolumn{5}{|c|}{$\begin{array}{c}\text { Calculated value of blockage pull- } \\
\text { out force }(\mathrm{kN}) \\
\text { Time }(\mathrm{d})\end{array}$}} & \multicolumn{5}{|c|}{ Calculation error } \\
\hline & & & & & & & & & & & & & & & \\
\hline & 7 & 14 & 21 & 28 & 35 & 7 & 14 & 21 & 28 & 35 & 7 & 14 & 21 & 28 & 35 \\
\hline & 1 & 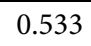 & & & & & & & & & & & & & $7.98 \%$ \\
\hline & 0.285 & 0.336 & 450 & 0.70 & & & & & & & & & & $9.09 \%$ & $6.15 \%$ \\
\hline $3 \#$ steel plate & 0.155 & 0.202 & 0.254 & 0.278 & 0.328 & 0.147 & 0.192 & 0.227 & 0.256 & 0.281 & $-5.47 \%$ & $-5.16 \%$ & $-10.68 \%$ & $-7.98 \%$ & $-14.40 \%$ \\
\hline
\end{tabular}

TABLE 14: Similarity rate of related variables.

\begin{tabular}{lcccc}
\hline Physical quantity & Symbol & Dimension & Prototype & Model \\
\hline Geometry size & $d, h, l$ & $\mathrm{~L}$ & 1 & $1 / n$ \\
Density & $\rho$ & $\mathrm{ML}^{-3}$ & 1 & 1 \\
Quality & $m$ & $\mathrm{M}$ & 1 & $1 / n^{3}$ \\
Force & $F$ & $\mathrm{MLT}^{-2}$ & 1 & $1 / n^{2}$ \\
Roughness & $R_{a}$ & $\mathrm{~L}$ & 1 & 1 \\
\hline
\end{tabular}

$$
F_{p}=i \cdot w
$$

Darcy's law is given by

$$
\begin{aligned}
v & =k \cdot i \\
\frac{F_{s p}}{F_{s m}} & =\frac{i_{p} w_{p}}{i_{m} w_{m}}=\frac{v_{p}}{v_{m}} \cdot \frac{k_{m}}{k_{p}} \cdot \frac{w_{p}}{w_{m}},
\end{aligned}
$$

where $F_{s}$ is the seepage force, $i$ is the hydraulic gradient, $G_{w}$ is the weight of the water in the soil under consideration, $k$ is the permeability coefficient, and $v$ is the permeability rate. $F_{s p}$ is the prototype seepage force and $F_{s m}$ is the model seepage force. Among them, the permeability coefficient is constant, and the permeability rate is related to time.

$$
\begin{aligned}
& \frac{v_{p}}{v_{m}}=n \cdot \frac{t_{m}}{t_{p}}, \\
& \frac{w_{p}}{w_{m}}=n^{3} .
\end{aligned}
$$

From Table 10 and formulae (9)-(11), it is concluded that

$$
\frac{t_{p}}{t_{m}}=n^{2} .
$$

5.1.2. Scale of Model Test Time considering Inertial Force. From Newton's second law of physics, we can get

$$
\begin{aligned}
& \frac{F_{t p}}{F_{t m}}=\frac{m_{p}}{m_{m}} \cdot \frac{a_{p}}{a_{m}}=n^{3} \cdot \frac{a_{p}}{a_{m}}, \\
& \frac{a_{p}}{a_{m}}=\frac{L_{p}}{L_{m}} \cdot \frac{t_{m}^{2}}{t_{p}^{2}}=n \frac{t_{m}^{2}}{t_{p}^{2}}
\end{aligned}
$$

In the same way, it can be inferred from Table 14 and formulae (13) and (14) that

$$
\frac{t_{p}}{t_{m}}=n
$$

Through comparison and analysis, we can see that the time scales under the two forces are quite different. According to the actual situation, in the process of deepwater silt consolidation or compaction, it is always in a saturated state, and the influence of the change in seepage force is relatively small compared to the influence of gravity. Under the action of gravity, the volume of the blockage changes, and the squeezing force between the sludge and the gate increases, so the inertial force should be mainly considered. Therefore, formula (15) should be selected as the time scale to consider.

\subsection{Verification of the Gate Silt Pull-Out Force Analysis Model.} Take 1\# steel plate model as an example, the proportion of silt, sand, small stone, and middle stone is $2: 1: 1: 1$, being kept for 7 days, and take the scale $n$ as 10 , then $b$ as $3 \mathrm{~m}$, and $i$ as $5 \mathrm{~m}$.

When considering the time scale under the influence of seepage force, $t$ is $700 \mathrm{~d}$ from formula (12), and then according to formula (9), $F p=F d=139.790 \mathrm{kN}$. Since $n=1$, $F M=0.419 \mathrm{kN}$, so $F p / F M=333=18.22 \neq 102$. It is further explained that the experimental results are not suitable for considering the time scale relation under the influence of seepage force.

When considering the time scale under the influence of seepage force, $t$ is $70 \mathrm{~d}$ from formula (15), and then according to formula (9), $F p=F d=53.500 \mathrm{kN}$. Since $n=1$, $F M=0.419 \mathrm{kN}$, so $F p / F M=127=10^{2} \approx 10^{2}$. Therefore, considering the time scale under the influence of inertial force, the scale condition of formula (6) is basically satisfied.

In the same way, other different similarity ratio applicability arguments can be checked. The results are shown in Table 15.

The analysis between the pull-out force simulation results and the initial test results through different similarity ratios $n$ basically satisfies the scale condition of formula (6). As the similarity ratio $n$ is larger, the pull-out force calculation results are closer to the target value $n^{2}$. It means that when the size is large enough, the simulated predicted value is closer to the true value.

The similarity ratio relationship verification further verifies the test results and the reliability of the proposed model. The pull-out force analysis model of the gate silt under the silt environment can be established to predict the pull-out force under different size conditions based on the test results of the small-size indoor model. 
TABLE 15: Verification of similarity ratio relationship of the pull-out force analysis model.

\begin{tabular}{lccccccc}
\hline$n$ & 5 & 10 & 15 & 20 & 30 & 40 & 100 \\
\hline$F_{H} / F_{M}$ & $5^{2.17}$ & $10^{2.1}$ & $15^{2.08}$ & $20^{2.07}$ & $30^{2.05}$ & $40^{2.04}$ & $100^{2.01}$ \\
\hline
\end{tabular}

Deep-hole gates are often in a deep water environment and the water level often changes. There are large water loads with loading and unloading cycles. The experiment in this paper is limited by conditions and only considers the effect of fixed water level, which is the main cause of error in prediction results and fluctuations. In the next step, the drawing force model will be revised and improved considering such factors as the action of the water head and the variation of water level, which is expected to identify the silting situation of the gate more accurately and provide more scientific guidance for decision-making of silting timing and related technical indicators of silting equipment.

\section{Conclusion and Prospect}

(1) Single source test results show that silt blockage has the greatest impact in silting and the mixture source test results show that when the proportion of silt, sand, small stone, and middle stone is $2: 1: 1: 1$, the sedimentation effect is the largest, both the blockage height and the blockage time have a linear positive correlation on the surface of the test results. The blockage height is the main influencing factor. Therefore, the blockage height should be strictly controlled in the gate operation. Ensure that $F=$ $\Sigma 0.1734 i-0.524 \times b$ is less than the abundant capacity of gate opening and closing force.

(2) The width of the steel plate has little effect on the pull-out resistance of the sediment, while the height of the sediment has a significant effect on it. Based on this, the pull-out resistance of the sediment can be simplified into a two-dimensional problem in the direction of height.

(3) Based on the model test results, a mechanical model of the pull-out force of the gate silt under the silting environment has been established. It has been verified that as the similarity ratio $n$ increases, the calculated pull-out force is closer to the target value $n^{2}$, indicating that when the size is large enough, the predicted value simulated is closer to the true value. And the real-time recognition technology for the impact of siltation for deep water gate can be formed, which can accurately guide the dredging of the gate.

\section{Data Availability}

All data included in this study are available upon request by contacting Li Hua (286166401@qq.com).

\section{Conflicts of Interest}

The authors declare that they have no conflicts of interest associated with this publication.

\section{Acknowledgments}

This work was financially supported by the National Natural Science Foundation of China (52009067) and the National Key Research and Development Plan (Subject no. 2016YFC0401607).

\section{References}

[1] L. Y. Liu and L. P. Wen, "Analysis on high dam large reservoir statistics in China," Water Conservancy Construction and Management, vol. 36, no. 9, pp. 12-16, 2016.

[2] Q. W, Han, Reservoir Sedimentation, China Science Publishing \& Media Ltd, BeiJing, China, 2003.

[3] H. M. Jian, J. C. Ni, and X. F Liu, Reservoir Sedimentation, The Yellow River Water Conservancy Press, ZhengZhou, China, 2004.

[4] J. M. Xie, Studies on the Evaluation of Reservoir Sedimentation Management, Tsinghua University, Beijing, China, 2012.

[5] Z. Niu, D. Y. Bai, J. Du, and Z. J. Wang, "A test on the friction of sluice gate in silted sediment," Journal of Sediment Research, vol. 1, pp. 20-28, 1996.

[6] G. B. Xu and X. F. Ren, "Study on similarity and modeling technique of model test for effect of sediment to lifting force of gate," Journal of Hydraulic Engineering, vol. 9, pp. 61-64, 2000.

[7] Y. Hou, Study on the Influence of Silt on Hydraulic Automatic Flap Gate, Northwest A \& F University, Xianyang, China, 2016.

[8] Y. Hou, X. Y. Zhang, and G. D. Xu, "Calculation of effect of silt sediment on the opening water level of the hydraulic automatic flap gate," China Rural Water and Hydropower, vol. 10, pp. 170-173, 2015.

[9] P. J. Wu and J. Wang, "Effects of sediment pressure on opening of hydraulic automatic control flap gate," Advances in Science and Technology of Water Resources, vol. 34, no. 4, pp. 79-81, 2014.

[10] B. Yuan, L. Xiong, L. Zhai et al., "Transparent synthetic soil and its application in modeling of soil-structure interaction using optical system," Frontiers in Earth Science, vol. 7, p. 276, 2019.

[11] B. Yuan, M. Sun, L. Xiong, Q. Luo, S. P. Pradhan, and H. Li, "Investigation of 3D deformation of transparent soil around a laterally loaded pile based on a hydraulic gradient model test," Journal of Building Engineering, vol. 28, no. 3, p. 101024, 2020.

[12] B. X. Yuan, M. Sun, Y. X. Wang, L. H. Zhai, and Q. Z. Luo, "Full 3D displacement measuring system for 3D displacement field of soil around a laterally loaded pile in transparent soil," International Journal of Geomechanics, vol. 19, no. 5, Article ID 04019028, 2019. 